\title{
Modelling distribution of flounder larvae in the eastern English Channel: sensitivity to physical forcing and biological behaviour
}

\author{
Alexei Sentchev ${ }^{1, *}$, Konstantin Korotenko $^{2}$ \\ ${ }^{1}$ Ecosystèmes Littoraux et Côtiers - FRE 2816, Université du Littoral-Côte d'Opale, 32 Avenue Foch, 62930 Wimereux, France \\ ${ }^{2}$ Marine Turbulence Laboratory, P.P. Shirshov Institute of Oceanology, 36, Nakhimovsky Prospect, Moscow 117851, Russia
}

\begin{abstract}
The Princeton Ocean Model coupled with a particle-tracking module is used to assess the effects of physical forcing and vertical migratory behaviour on the transport and dispersion of larvae in the region of freshwater influence (ROFI) of the eastern English Channel (EEC). Results of numerical modelling are compared with the observed concentrations of flounder Pleuronectes flesus larvae. The simulations show that accumulation of neutrally buoyant particles occurs on the ROFI margin, $20 \mathrm{~km}$ off the French coast. Tides and freshwater input induce the net along-shore northward transport. Tidal currents modulate the magnitude of horizontal transport, whereas the freshwater input controls the location of accumulation zones. The vertical migration of particles causes a significant departure from the passive transport pattern and modifies the intensity of dispersion. The diurnal (light dependent) migration tends to decrease the magnitude of the cross-shore dispersion of particles. When the vertical migration is controlled by the tidal (sea level variation) cycle, particles move northward faster, and exhibit less dispersion. The migratory behaviour synchronised with the tidal currents (ebb/flood cycle) produces a relatively slow northward migration and a low dispersion in both along- and cross-shore directions. This suggests that vertical migratory behaviour could control the intensity of dispersion and the relative dominance of either retention or downstream advection of the larvae in the EEC.
\end{abstract}

KEY WORDS: Larval transport · Vertical migration $\cdot$ Particle tracking $\cdot$ Tides $\cdot$ English Channel

\section{INTRODUCTION}

The role played by various physical processes in fish early life history is currently an area of active research. Among a variety of physical (abiotic) conditions, we considered 2 closely linked aspects that can have a large effect on recruitment. The first involves larval transport by non-stationary flow field and the second involves the response of larval behaviour to changes in environmental conditions. During the early life stages, pelagic larvae of many commercially valuable fishes execute horizontal migrations from spawning areas to estuarine nursery grounds. The influence of physical forcing on larval development has been studied by many authors. Larval growth and abundance may vary in response to wind and tidal circulation on different time scales (Nielsen et al. 1998, Van der Veer et al. 1998). The role that physical variability plays in observed abundance and recruitment of flatfish populations was examined by Werner et al. (1997). The effect of tides on larval transport and recruitment was documented by Brown et al. (2000) and Jenkins et al. (2000). Xie \& Eggleston (1999) discussed the potential role of wind forcing on larval transport, while Boeuf \& Payanb (2001) reported an influence of water salinity on fish development.

Measurements of the behavioural response of the larvae to changes in their habitat are demanding because of the difficulties in estimating in situ larval abundances, especially when simultaneous monitoring 
of the physical factors affecting the abundances is required. Factors which may influence the vertical migration include light, temperature, variation in hydrostatic pressure, speed and direction of the flow, availability of food, predation, turbidity and turbulence. To assess the influence of different environmental factors on larvae, laboratory experiments have been conducted in which larvae were observed under controlled conditions. Their response to changes in physical parameters was then extrapolated to behaviour in natural habitats (Burke et al. 1995, 1998).

A particle-tracking model coupled with a hydrodynamic model is a particularly efficient tool for examining the role played by various physical processes in combination with individual behaviour of sea organisms. Using the particle-tracking approach one can account for different migration cues, and study changes in the description of the larval transport in comparison with the transport of passive larvae. In this way, Franks (1992) has found that a horizontal or vertical patchiness of organisms may arise at fronts through retention and accumulation zones in accordance with the swimming behaviour of the organisms. This result has been obtained in the framework of a 2-dimensional model of a steady cross-frontal flow. Hill (1994) has considered a transport-inducing interaction between diurnal vertical migration of marine organisms and the $\mathrm{S}_{2}$ tidal currents. Simulations of Jenkins et al. (1999), involving several vertical migratory behaviours of particles, revealed that the vertical migration does not influence the larval transport in Port Philip Bay (southern Australia). Bartsch (1988) has obtained different results in numerical simulations of the drift routes of herring larvae across the North Sea. His model, although 3-dimensional, included only residual advective fields and was thus unable to account for the migration-tide interaction. However, the transport pathways of larvae were found to be significantly affected by the interaction of the vertical migration with the mean current shear. A sensitivity of larval transport to vertical migratory behaviour of the larvae has been investigated by Bartsch \& Coombs (2001) in the North Atlantic and by Graaf et al. (2004) in the North Sea, both by means of numerical modelling.

The freshwater inflow from a number of rivers on the northern coast of France gives rise to a haline front separating offshore waters of Atlantic origin from the region of freshwater influence (ROFI). Within the ROFI, the buoyancy input is responsible for producing a physical regime, which is different from that of the offshore waters. A variety of ROFI systems and their distinctive dynamical features were described in some detail by Simpson (1997). In a recent study, Sentchev \& Korotenko (2004) developed an accurate numerical representation of the geometry, hydrology and circula- tion in the eastern English Channel (EEC). They have shown that, within the ROFI of the EEC, a certain combination of tides and buoyancy input produces patchiness in spatial distribution of particles. An along-coast northward particle migration was detected in the numerical experiments and confirmed by the field observations of larval abundance. According to field measurements, the main spawning areas of flounder Pleuronectes flesus in the English Channel are located within the central part of the domain, while the larvae are found most often in the coastal nursery grounds (Van der Land 1991, Grioche et al. 1997). Mechanisms of larval transport from source to nursery grounds are poorly understood.

The present study can be viewed as an extension of the above-mentioned work of Sentchev \& Korotenko (2004), with emphasis on the interaction between the vertical migration of particles, representing the larvae, and tidal currents. We investigate horizontal larval transport and dispersal driven by a combination of tides and freshwater input and influenced by the vertical migratory behaviour of pelagic organisms. The behaviour is restricted to vertical migration driven by day-light variability and tidal motions (sea surface height and currents) observed in the English Channel.

\section{MATERIALS AND METHODS}

Hydrodynamic model. In this study we use the sigma-coordinate Princeton Ocean Model (POM) to simulate tidal circulation in combination with realistic freshwater runoff within the model domain shown in Fig. 1a. The detailed description of the model is given by Blumberg \& Mellor (1987). POM solves finitedifference analogues of the primitive equations in 3 spatial dimensions with fully prognostic temperature and salinity fields, thus allowing time-dependent baroclinic motion. A free surface, essential for modelling tides, is also included. The entire region of the EEC, including the Strait of Dover and the southern part of the North Sea, is represented on a horizontal grid with homogeneous spacing of $2 \mathrm{~km}$. The bottom topography has a complicated geometry, with numerous shallow banks separated by a series of $50 \mathrm{~m}$ deep basins, both oriented in the along-shore direction (Fig. 1a). The model uses the 'Arakawa $\mathrm{C}^{\prime}$ differencing scheme for the momentum equations in the horizontal plane, a set of 21 vertical sigma levels, distributed so as to provide enhanced resolution in proximity to the surface and seabed, and the level 2.5 turbulence model of Mellor \& Yamada (1982). A quadratic bottom-friction approximation is used with a uniform drag coefficient of 0.0025, usually adopted for the English Channel (Werner 1995). 

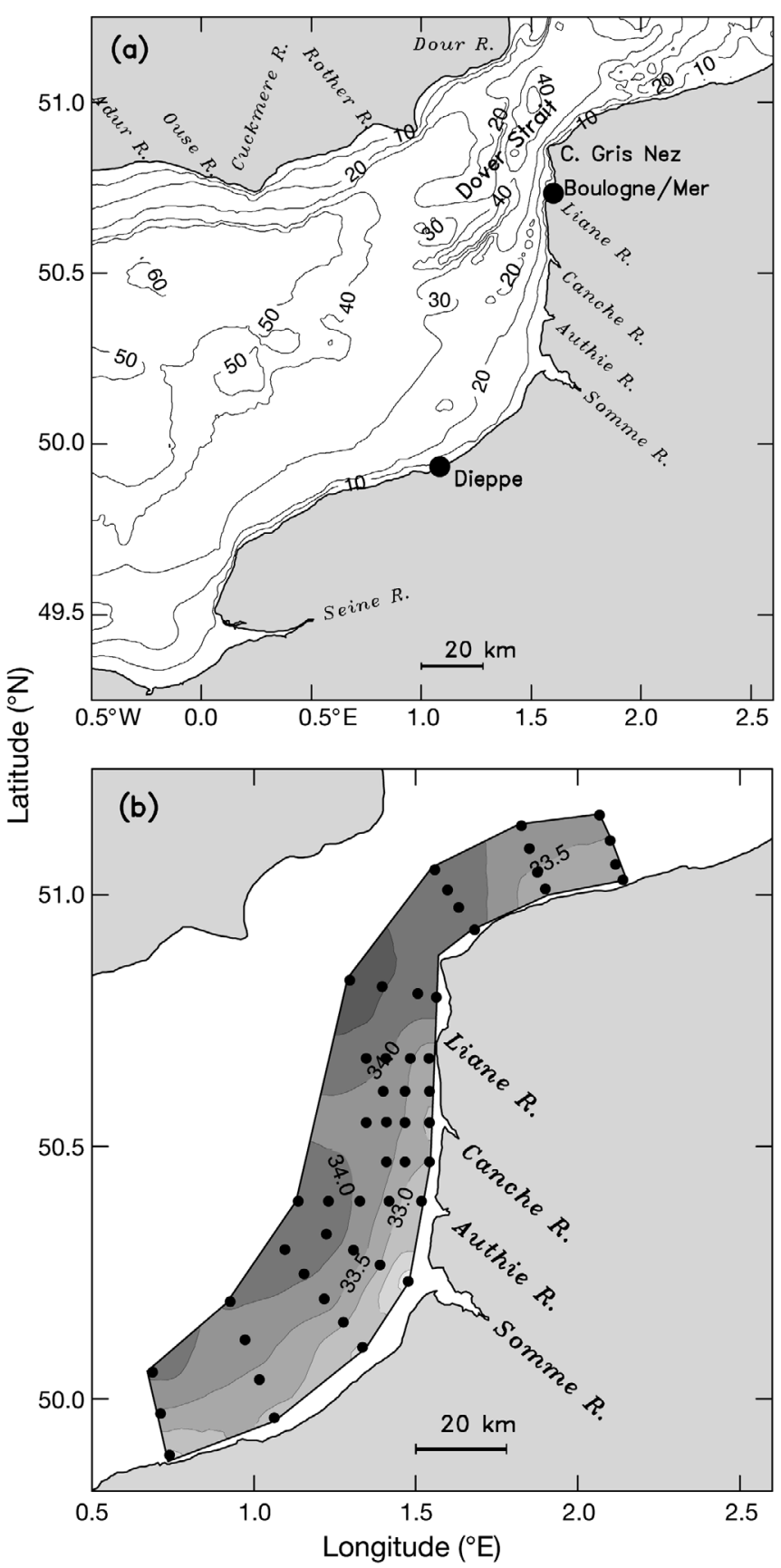

Fig. 1. (a) Bathymetry of the model domain (eastern English Channel). Contour interval is $10 \mathrm{~m}$. Major rivers (R.) contributing to the buoyancy input to the domain are shown. (b) Surface layer ( $1 \mathrm{~m}$ thick) salinity (psu) distribution from the field experiments conducted from 2 to 5 May 1995. Locations of sampling stations are shown (solid circles)

Water flow through the EEC is a combined result of the interaction of astronomical tides, freshwater discharge, meteorological forcing and non-tidal sea-level changes. A haline front, separating offshore waters of Atlantic origin from near-shore, low-salinity waters, is one of the most significant features of the EEC
(Fig. 1b). The model reproduces the front's position and its spatial extension reasonably well. Most of the freshwater inflow into the eastern channel comes from the Seine, Somme, Authie and some other rivers on the north-eastern coast of France and occurs in winter to early spring (Fig. 2a). During the period of numerical experiments, the cumulative inflow rate is of the order of $1500 \mathrm{~m}^{3} \mathrm{~s}^{-1}$ (Fig. 2b). Freshwater input from rivers on the English coast is much less important (about $4 \%$ ). Its effect on the transport and dispersion in the channel was considered by Sentchev \& Korotenko (2005). Fig. 2c shows winds measured in April and May 1995 at Boulogne light tower during the same period.

The sea level variation inside the model domain is predominantly semi-diurnal (Fig. 2d). To simulate tidal motions, tidal forcing with 3 primary semi-diurnal astronomical constituents, $\mathrm{M}_{2}, \mathrm{~S}_{2}, \mathrm{~N}_{2}$, and 1 non-linear constituent, $\mathrm{M}_{4}$, was introduced along the open boundaries. A gravity-wave radiation condition was used to specify the normal component of the depth-averaged current at the model open boundaries, according to Flather's (1976) method. Elevations and normal velocities at the open boundaries for the individual constituents were determined from a 2-dimensional finiteelement spectral tidal model. Tidal forcing for this model, in turn, was extracted from the global Finite Element Solution, Version 2.1, of 1995 (FES95.2.1) tidal database (Le Provost et al. 1995).

Modelling results were validated against the tides observed in 11 ports located in the eastern channel, surface current velocities measured by the OSCR HF radar in the Strait of Dover, and, finally, against the observed salinity distribution derived from the extensive field experiments conducted in the spring of 1995 (Sentchev \& Korotenko 2004).

Particle-tracking model. A Lagrangian particletracking technique includes the random-walk approach that is significantly more effective than the finite-difference method in describing qualitatively the spatial distribution of tracers. Schematically, the algorithm for updating particle coordinates is the following: every time step, a total of $N^{\mathrm{p}}$ particles are moved in the 3-dimensional Cartesian reference frame by an advective translation a added to a diffusive jump $\eta$. The advective movement within a grid cell is determined by linear interpolation of the velocity values from the 8 vertices of the grid cell, and computation of the displacement vector as a product of the interpolated velocity vector and the time step $\Delta t$. A diffusive jump of particles (random displacement due to sub-grid fluctuations of velocity) along each axis is determined in different ways. Along the horizontal axis $i(i=1,2)$, the 'naïve random walk' (NRW) expression was used to generate diffusive jumps, $\eta=\gamma(2 K \Delta t)^{1 / 2}$, where $\gamma$ is a vector of size $N^{\mathrm{p}}$ whose components are computed by 

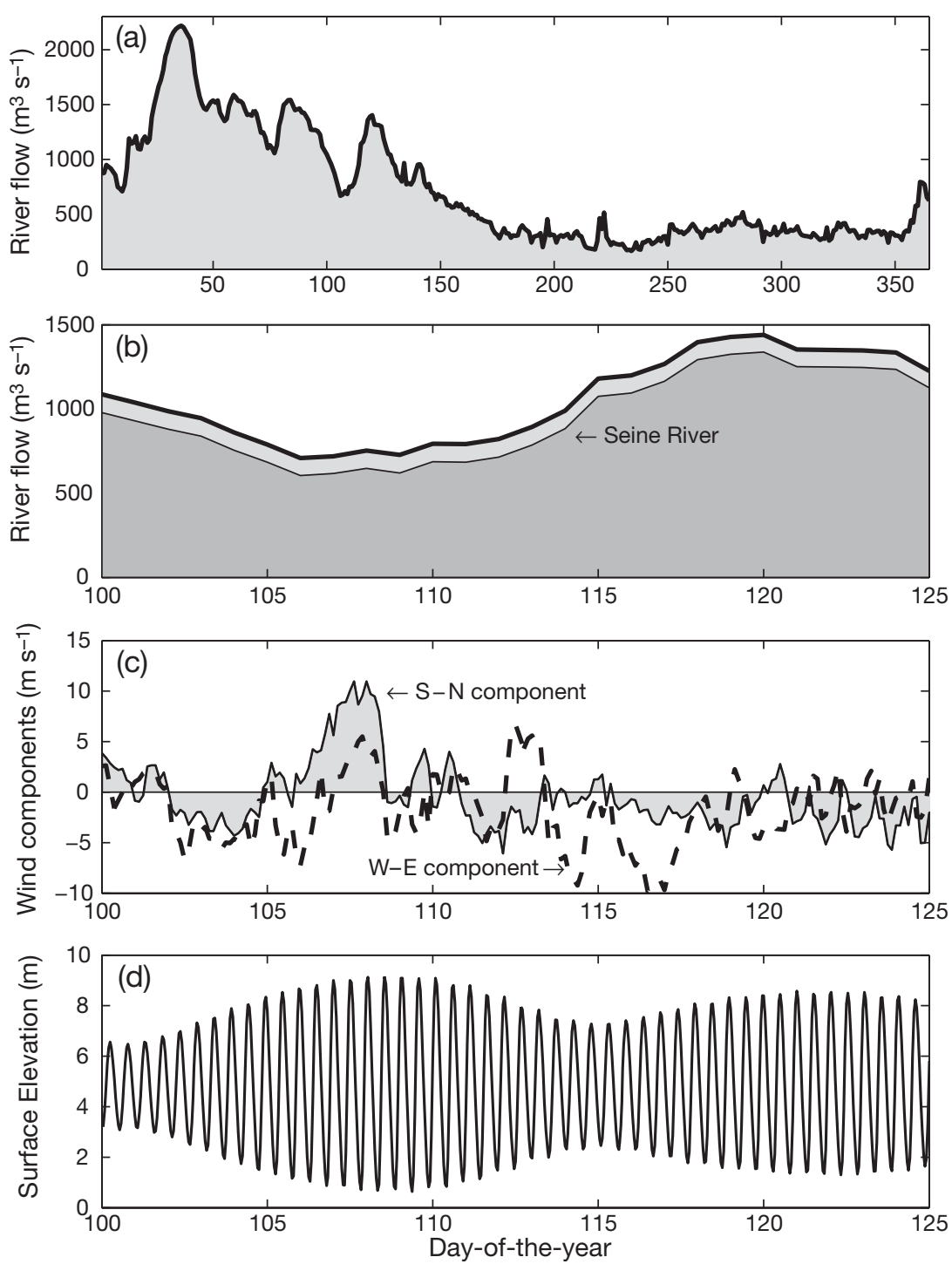

Fig. 2. Environmental data: (a) daily averaged values of the freshwater runoff in 1995 from the rivers located on the French coast between the mouth of the Seine and Cape Gris Nez and (b) the same values, but for the period of numerical experiments (thin line: Seine River; thick line: all rivers). The data are available on the website of the 'Seine-aval' national scientific project (http://seine-aval.crihan.fr) and the National Water Resources Society (www.eau-artois-picardie.fr). (c) Wind measurements were made at Boulogne light tower (Met-office data). Positive velocities are from the south to north (S to N) and from the west to east (W to E). (d) Sea surface tidal variation in Boulogne is based on historical observations tion. The following expression, adopted from Visser (1997), is used to simulate vertical displacements of particles: $\eta=K^{\prime}(z) \Delta t+\gamma\left[2 K\left(z^{*}\right) \Delta t\right]^{1 / 2}$. The CRW model includes a deterministic component and a diffusive, or random, component. The deterministic component causes a net displacement of the centre of mass of the neutrally buoyant particles toward increasing diffusivity at a rate $K^{\prime}$ (local gradient of $K$ in the vertical direction), thus allowing avoidance of the artificial particle accumulation within layers of low vertical diffusivity. The diffusion coefficient $K$ in the CRW model is estimated from the diffusivity profile at a vertical coordinate $z^{*}$ shifted from the particle coordinate $z$ by a small distance $1 / 2 K^{\prime} \Delta t$. We recognise that the CRW model could be used for simulating horizontal displacements. However, as we have assessed, within the ROFI, the largest horizontal and vertical diffusivity gradients are of the order of $10^{-3}$ and $10^{-1} \mathrm{~m} \mathrm{~s}^{-1}$, respectively, suggesting that the effect of $K_{\mathrm{H}}^{\prime}$ on horizontal distribution of particles is negligible, given the model grid spacing and time step.

The horizontal and vertical diffusion coefficients, $K_{\mathrm{H}}$ and $K_{\mathrm{V}}$, as well as the mean current velocity components $(u, v, w)$ are provided by the hydrodynamic model described in the previous section. The model computes the horizontal diffusion coefficients from the Smagorinsky (1963) formulae, while the vertical diffusivity is obtained from the level 2.5 turbulence closure scheme of Mellor \& Yamada (1982). Thus, 3-dimensional dynamic fields are used as forcing in the particle-tracking model, which produces particle coordinates at every time step.

a random-number generator (RNG), then converted to yield the Gaussian distribution with zero mean and unit standard deviation, and $K$ stands for the timedependent horizontal diffusivity along each axis.

The water flow in the EEC is a combination of tidal motions, freshwater input and wind-driven circulation. This forcing contributes to generation of a non uniform vertical diffusivity profile, and therefore requires the use of the 'consistent random walk' (CRW) model (Hunter et al. 1993, Visser 1997) in the vertical direc-
The time step $\Delta t$ for particle tracking is $360 \mathrm{~s}$. This value satisfies the numerical integration criterion (Visser 1997), prevents particle jumping $>1$ grid cell, and thus guarantees an accurate estimate of particle displacement in each of 3 directions. A particle reflection condition is implemented at the model rigid boundaries in all simulations. Particles leaving the model domain through the open boundaries are assumed to be lost.

Larva sampling. To improve the knowledge of the spatial distribution of spawning and nursery grounds 

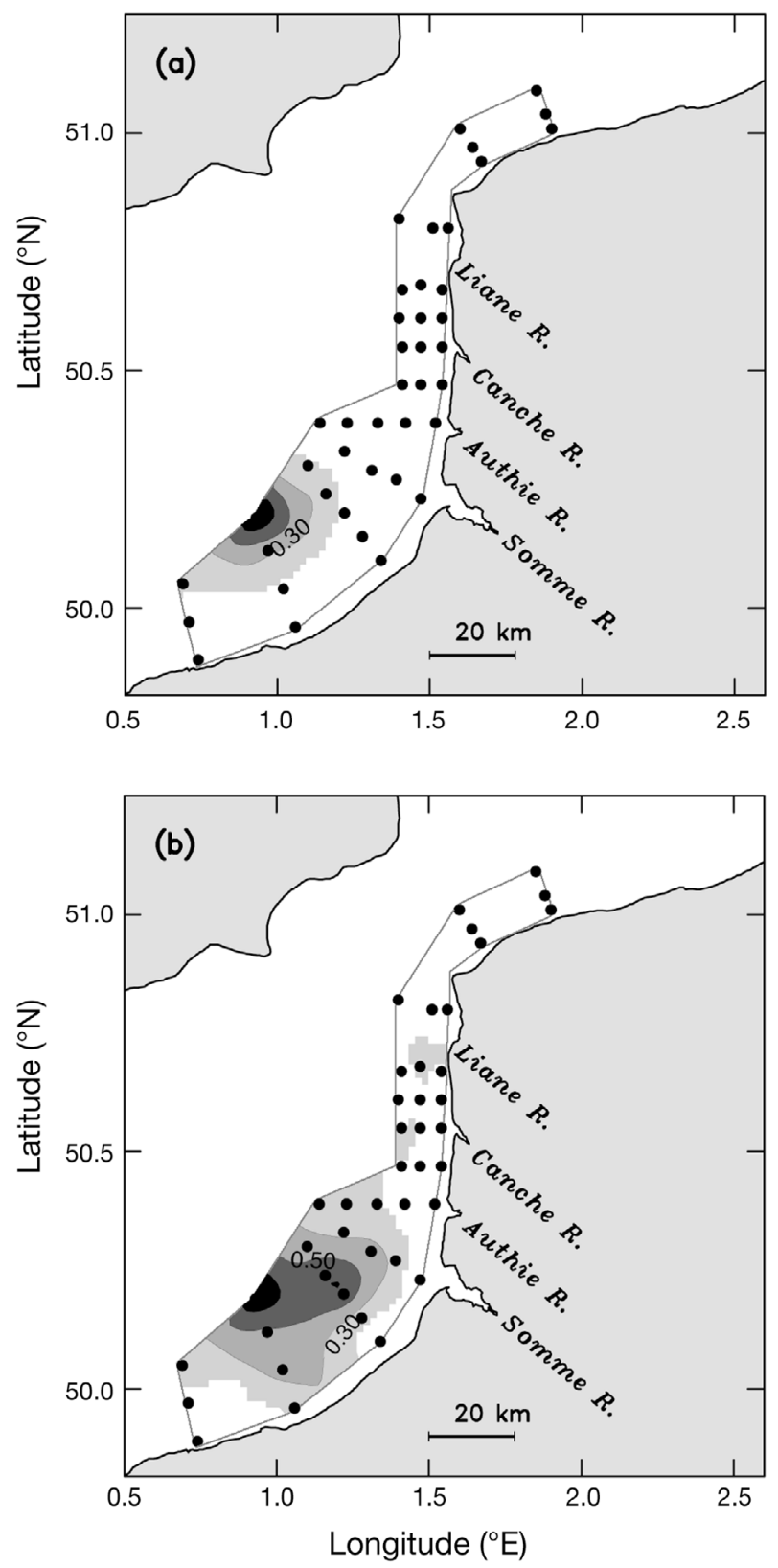

of flounder Pleuronectes flesus in the EEC, and to clarify mechanisms that might control the larval transport from source to nursery grounds, an extensive larval transport field experiment was organised in spring 1995. Two surveys, including cross-shore sections in the vicinity of the French coast (Fig. 1b), were conducted from 11 to 13 April and 2 to 5 May 1995. The description of the field experiment can be found in some detail in Grioche et al. (1997).

We present in Fig. 3 the flounder larval abundances obtained by interpolation of the raw data of Grioche et al. (1997), without introducing any hypothesis of patchiness in spatial distribution. Abundances, expressed in numbers per $100 \mathrm{~m}^{3}$, were normalised by the maxi-

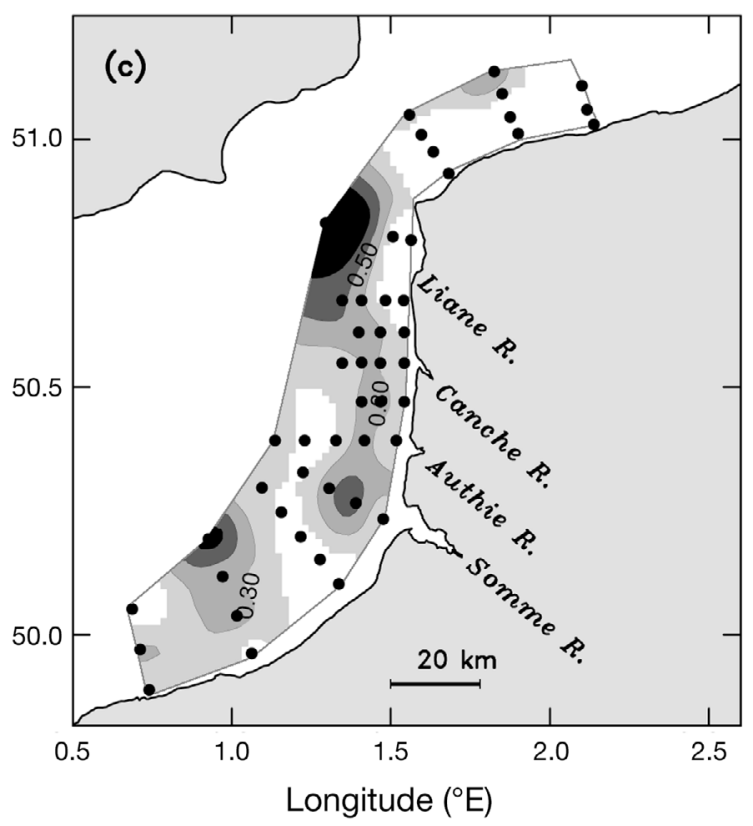

Fig. 3. Pleuronectes flesus. Contour plots of the abundances of flounder larvae for different development stages: (a) eggs, (b) Stage 2 larvae, sampled during the first survey (April 1995), and (c) Stage 3 larvae, sampled during the second survey (May 1995). Abundance values presented were normalised by the maximum value for each plot $(15,30$ and 25 ind. per $100 \mathrm{~m}^{3}$ for $\mathrm{a}, \mathrm{b}$ and $\mathrm{c}$, respectively). Sampling stations are shown (solid circles). The contour interval is 0.2

mum value in each plot. Fig. 3a shows that flounder eggs formed a patch, $40 \mathrm{~km}$ westward of the Somme estuary (spawning area), with a maximum abundance of 15 eggs per $100 \mathrm{~m}^{3}$. Eggs were absent elsewhere in French coastal waters. The larvae of Stage 2 (1 wk old) were also found in a single patch extending in a northeast direction (Fig. 3b). The maximum abundance of the larvae, up to 30 larvae per $100 \mathrm{~m}^{3}$, and fish eggs were detected at the same location. The spatial distribution of Stage 3 larvae, sampled in May 1995 (Fig. 3c), allows us to speculate that a northward larval advection along the French coast occurred. We can also deduce an ability of the larvae to exert shoreward migration. In May, high abundances were found within the ROFI, in 
the low-salinity water, rich in chlorophyll $a$. The dominant wind was north-east during the field experiments (Fig. 2c) and could not explain larval drift toward the north. On the contrary, survivorship-mortality patterns can affect the observed distribution of abundances, but our knowledge about such spatial patterns in the EEC is poor to date. We must also recognise that the sampled region covers only a part of the spawning grounds presented in Fig. 3a. That is why a hypothesis of larval advection, derived from the observations (Fig. 3), might be adopted with a high degree of uncertainty.

Vertical migration of the larvae. The variability of migration pathways for some species (Limanda limanda and Pleuronectes flesus) has been observed in the North Sea, and a hypothesis showing the influence of larval behaviour on the vertical distribution has been proposed by Campos et al. (1994). Burke et al. (1995) and Boss et al. (1995) have documented that flounder larvae are found within the water column on flood and in the bottom layer on ebb. This behaviour facilitates shoreward displacement of larvae and even their upstream propagation within the estuary (Boss et al. 1995). A preliminary study of Grioche et al. (2000) indicated a possible light-dependent diurnal cycle in vertical displacement, with motions toward the bottom at daybreak and back up the following nightfall. Such migration might help to avoid visual predation.

As no comprehensive theoretical model of vertical migration pattern exists, we have adopted 2 simple models of vertical migration that are consistent with distributions of flounder larvae observed by different authors in different regions. The first model describes diurnal migration that is locked on the day-night cycle. It is assumed that the deepest part of the migration cycle is centred upon local nightfall (19 h UT in April) and that particles are rising towards the surface after nightfall and falling toward the bottom during daytime (Fig. 4a). Since the day in April is slightly longer than the night, the duration of upward motion is shorter and the corresponding velocity $(2 \mathrm{~m}$ $\mathrm{h}^{-1}$ ) is slightly higher than the downward velocity $\left(1.7 \mathrm{~m} \mathrm{~h}^{-1}\right)$. Both, the upward and downward migratory velocities are kept constant during the total period of simulations, allowing the larvae to exert regular vertical oscillations within the $25 \mathrm{~m}$ thick water layer (Fig. 4a).

The second migration model is linked to semidiurnal tidal cycle. Three different situations are considered. In the first situation, the sign of vertical velocity depends upon the hydrostatic pressure tendency: particles sink at a constant speed during falling tide and move up during rising tide (Fig. $4 \mathrm{~b})$. In the second situation, the vertical migration is related to the tidal current cycle, which advances the sea surface height by approximately $2 \mathrm{~h}$ (Fig. 4c). In the third situation, we reverse the sign of vertical migratory velocity, thus allowing particles to sink during flood and to rise during ebb (Fig. 4d).

Numerical simulations. Several particle model runs are conducted under different tidal conditions, including a primary and a secondary neap to spring cycle (Fig. 2d), with or without freshwater inflow and wind
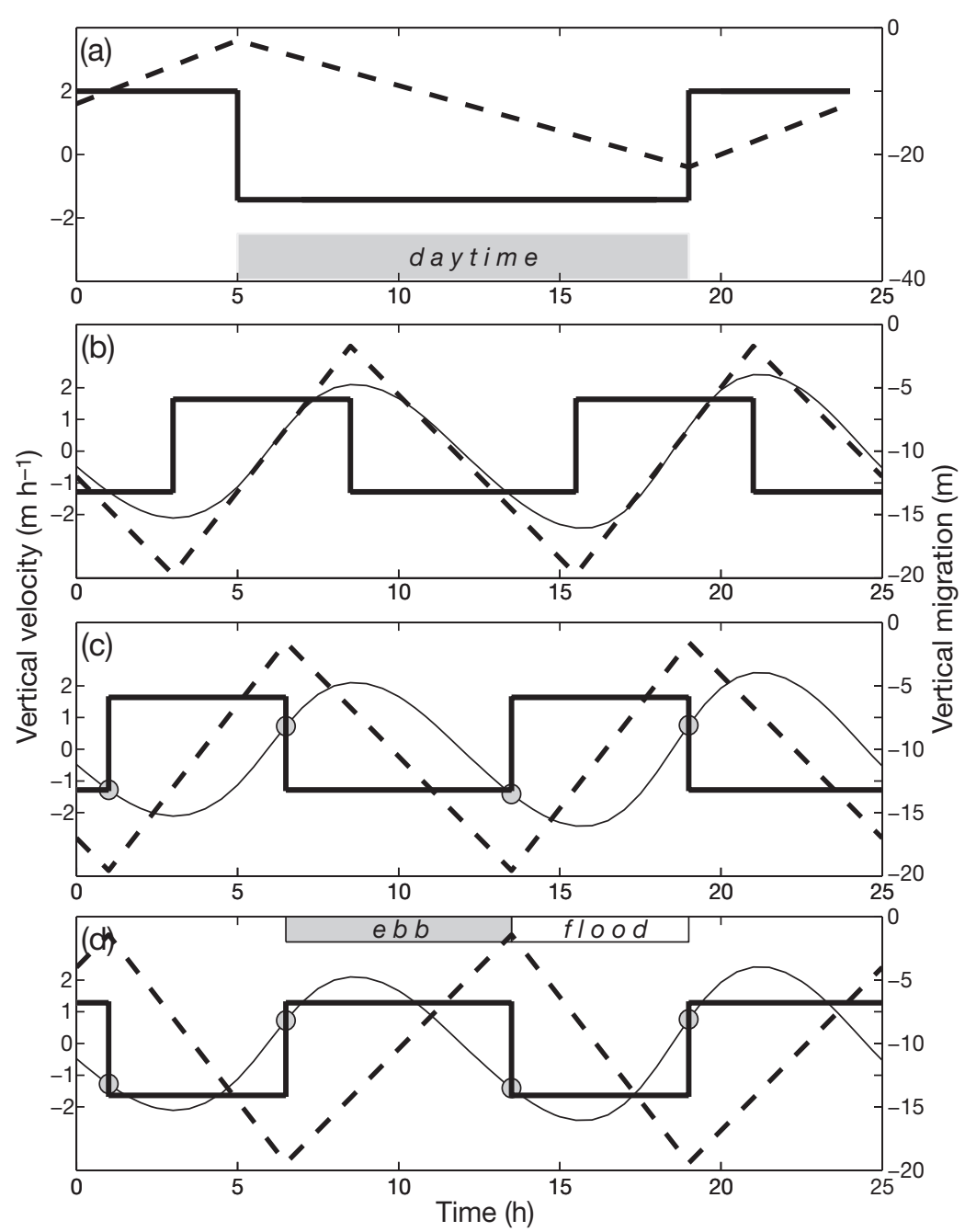

Fig. 4. Time-dependent vertical swimming velocity (thick solid line) assigned to particles in numerical experiments, and vertical displacement of particles (dashed line) relative to the sea surface. (a) Diurnal (light dependent) vertical migration, (b) tidally cued (sea level-locked) migration, (c,d) migration synchronised with tidal currents. The signs of vertical migratory velocities are reversed in c and d. Positive velocity is toward the surface; negative is toward the bottom. The thin line shows sea level variation in Boulogne on 11 April 1995; circles show the instant of current reversal 
forcing. We also consider 3 scenarios accounting for larval behavioural response to light conditions, hydrostatic pressure and current variations. To assess the role that physical forcing terms play in particle dynamics, simulations are performed first with neutrally buoyant particles. A set of 960 (8 per grid box) particles was released over a small region $\left(24 \times 20 \mathrm{~km}^{2}\right)$ in front of the Somme estuary (see Fig. 5a) and tracked during a $25 \mathrm{~d}$ period. To examine the sensitivity of transport pathways and dispersion to a number of particles used in simulations, a set of 9600 particles was released within the same region. At release, particles are homogeneously distributed within a 2 m thick layer, with the upper limit at $1 \mathrm{~m}$ below the surface. Tidal motions and freshwater input, used in all the simulations, match the conditions corresponding to the period of the field experiments (Fig. 2b,d). Observed (Fig. 2c) and synthesised wind forcing were introduced in some model runs. The resultant distributions of particles are presented quantitatively in terms of the number of particles within a horizontal model grid cell by integrating the abundances vertically from surface to bottom. Additional simulations are performed with 960 particles; these enable vertical motions relative to the flow, with vertical velocity equating to the swimming behaviour of larvae. Appropriate tidal and freshwater forcing were used in these simulations.

To quantify the dispersion of particles and to discern the influence of vertical behaviour on the dispersion, we apply a principal component analysis (PCA) technique (Emery \& Thomson 1997) to the horizontal distribution of particles at the end of the $18 \mathrm{~d}$ tracking period. This allows us to identify the main axes along which the dispersion of material is extreme. The distortion of a particle group is quantified by a horizontal covariance matrix, the components of which account for the covariances between particle displacements relative to their centre of mass. The dispersion is extreme in the direction of the semi-major axis, whereas its length gives the root-mean square (rms) displacement.

\section{RESULTS}

\section{Transport of neutrally buoyant particles}

Fig. 5 shows the spatial distribution of particles at the end of an $18 \mathrm{~d}$ tracking period. The model results indicate that under the appropriate forcing, including the neap to spring tidal cycle and buoyancy input, particles are transported northward. The trajectory of displacement of the centre of mass of the ensemble of particles reveals that, in the near-shore sector associated with the ROFI, the dominant direction of drift is north- ward. The highest concentrations of particles (up to 6 per grid box) are found $20 \mathrm{~km}$ offshore, on the margin of the ROFI, defined according to surface salinity, ranging between 34.0 and 34.5 psu. Particles start leaving the domain through the northern model open boundary after $16 \mathrm{~d}$. We limited the analysis to the $18 \mathrm{~d}$ period. This allowed us to limit the bias of statistics due to the loss of particles.

When a set of 9600 particles is released within the previous zone at the same phase of the tidal cycle, the transport patterns look similar. Most particles are transported northward, slightly toward the French coast, then northward along the coast, with the highest concentrations detected again on the ROFI margin (Fig. 5b). Trajectories of the centre of mass of 2 particle ensembles (960 and 9600 particles) and the shape of the particle distribution look rather similar in both simulations.

To assess the role of buoyancy forcing in particle dynamics, tidally forced simulations were performed without freshwater input. In this case, model results do not reveal any accumulation of particles $20 \mathrm{~km}$ offshore. On the contrary, particles move shoreward and tend to be concentrated in the vicinity of the French coast, thus providing a very different distribution (Fig. 5c). The $\mathrm{N}$ to $\mathrm{S}$ (along shore) and $\mathrm{E}$ to $\mathrm{W}$ (cross shore) extensions of this patch are of the order of 120 and $45 \mathrm{~km}$, respectively, and are comparable with those shown in Fig. 5a,b.

The wind forcing, corresponding to observations available in Boulogne, in conjunction with buoyant and tidal forcing, produces small perturbations of the trajectory of displacement of the centre of mass of particles and modulation of spatial distribution of particles relative to the coast (results not shown). The upwelling-favourable ( $\mathrm{N}$ to $\mathrm{E}$ ) wind tends to decrease the rate of northward migration, inducing a weak offshore component. Wind in the opposite direction (SW) generates coastal downwelling and enforces the northward and shoreward migration of particles.

\section{Transport of vertically migrating particles}

The computations were repeated with vertically migrating particles. This 'active' behaviour of particles simulates the ability of organisms to float, sink, or swim relative to the water motion. Particles were released within the area that was used in the previous experiments (Fig. 5a). Modelling results indicate that the vertical migration may cause a significant departure from the passive particle transport pattern. The essential differences are illustrated in Fig. 6a-d.

When the diurnal (light dependent) vertical migration is introduced, the rate of transport and the shape 

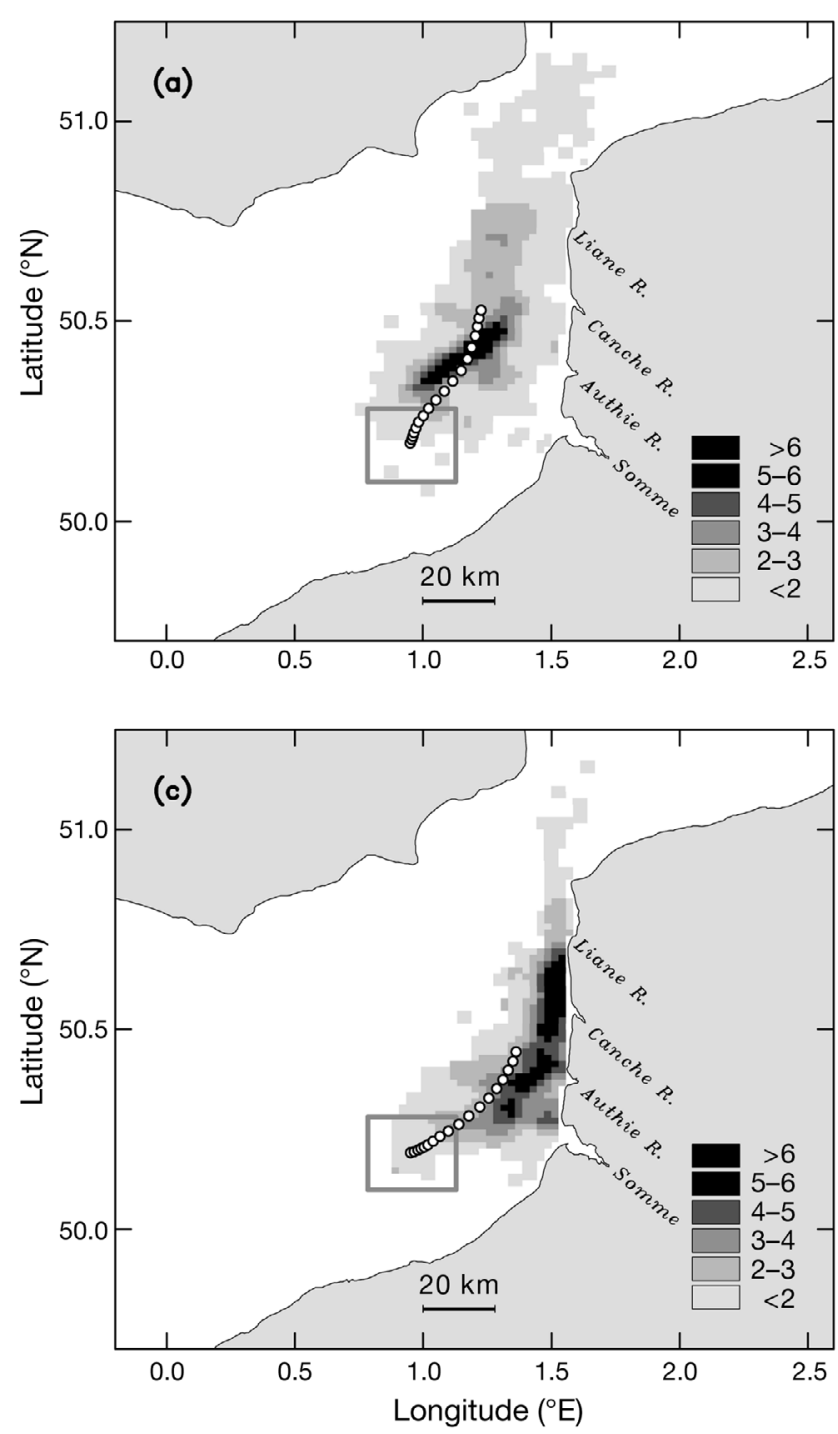

of spatial distribution of particles change (Fig. 6a). The majority of particles are confined to the margin of the ROFI zone, with maximum concentrations ( $>6$ per grid cell) found at a distance of $20 \mathrm{~km}$ offshore. Only a small amount of particles is found in the vicinity of the coast. The trajectories of displacement of the centre of mass of 'active' and 'passive' particles appear to be similar, but reveal a noticeable difference in the rate of migration. 'Active' particles tend to move faster and need $2 \mathrm{~d}$ less to attain the location of the centre of mass of 'passive' particles at the end of the $18 \mathrm{~d}$ period. Globally, the horizontal distribution of vertically migrating particles shows higher concentrations along an axis parallel to the shoreline, distant from the coast by 20 to $25 \mathrm{~km}$, and higher speed of northward migration.

Fig. 6b shows the behavioural response of modelled particles to tidally cued vertical migration, i.e. the migration synchronised with the tidal cycle of sea sur-

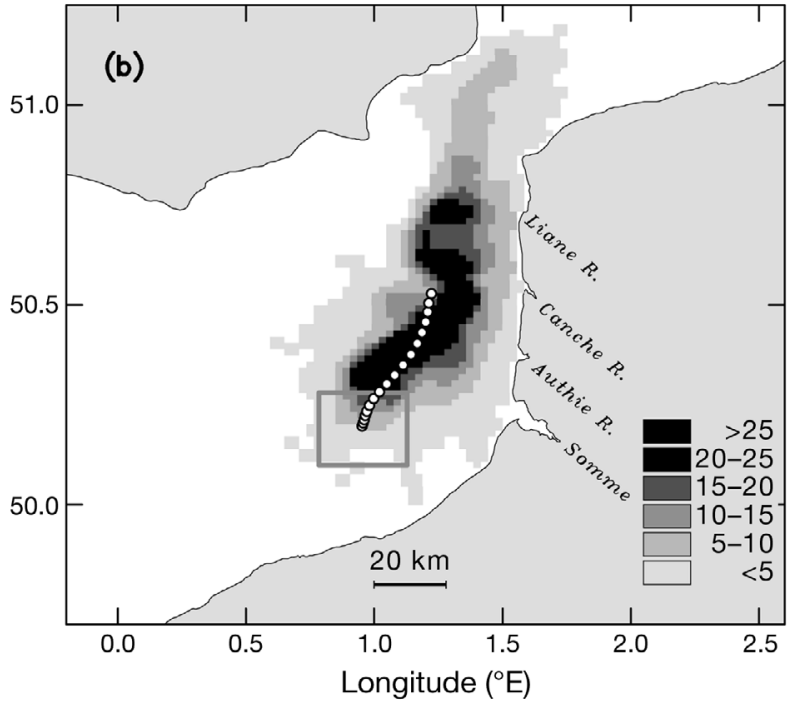

Fig. 5. Particle concentrations (no. per grid cell) after $18 \mathrm{~d}$ tracking of (a) 960 particles and (b) of 9600 particles, under realistic tidal and buoyancy forcing. (c) Particle concentrations in the flow without freshwater forcing. At release, particles are homogeneously distributed within a surface $2 \mathrm{~m}$ thick layer ( $1 \mathrm{~m}$ below the surface) in the area shown by the square. Location of the square corresponds to the spawning area of flounder. Particles are completely passive. Circles show the Lagrangian residual displacement of the centre of mass of the particle ensemble. The time interval between 2 successive locations of the centre of mass is 2 tidal cycles $(24.8 \mathrm{~h})$. The centre of mass matches the average of the horizontal coordinates of particles

face elevation. After $18 \mathrm{~d}$ of tracking, the spatial distribution of particles reveals spreading in the along-coast direction and the northward advection, with a local maximum of particle concentration (up to 6 per grid box) found at a distance of $20 \mathrm{~km}$ offshore. The rate of northward advection of the centre of mass is the highest in comparison with all previously discussed situations. The centre of mass is located $80 \mathrm{~km}$ northeastward of the release point, and the trajectory of its displacement shows that particles spend $7 \mathrm{~d}$ less to reach the location occupied by neutrally buoyant particles at the end of the tracking period. Moreover, the trajectory of the centre of mass is only $13 \mathrm{~km}$ away from the coast after $12 \mathrm{~d}$ of tracking (Fig. 6b), indicating that some portion of the particles can reach the coast by the middle of the tracking period.

In the third scenario, the vertical migration is synchronised with the tidal current cycle, which advances the 

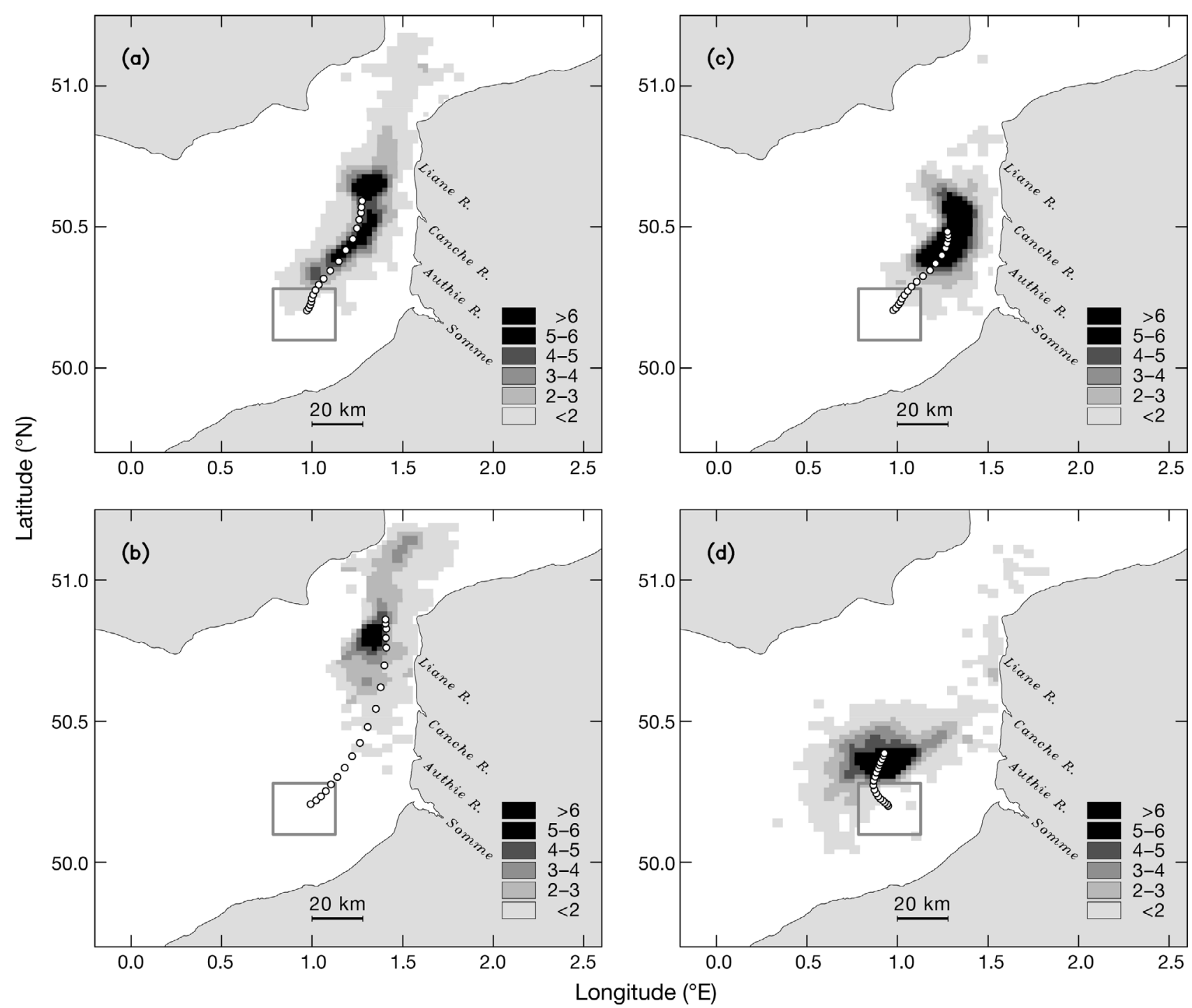

Fig. 6. Particle concentrations (no. per grid cell) after $18 \mathrm{~d}$ tracking with various behavioural models of vertical migration: (a) diurnal (light-locked) model, (b) tidal sea level-locked model, (c) tidal current-locked model, and (d) tidal current-locked model with the opposite sign of vertical swimming velocity. Particles were released in the area shown by the square. Circles show the Lagrangian residual displacement of the centre of mass of particles. The time interval between 2 successive locations of the centre of mass is 2 tidal cycles $(24.8 \mathrm{~h})$

sea surface elevation by approximately $2 \mathrm{~h}$ (Fig. 4c). Particles executing such migration remain close together and retain their initial concentration (8 per grid box) for a long time during the tracking period. The spatial distribution reveals a low-spreading, along-coast orientation of particles in the group, with high concentrations found again $20 \mathrm{~km}$ offshore. Few of the particles can be seen in the vicinity of the coast. The speed of northward migration in this group of particles is 2 times smaller than in the case of tidally cued migration.

Fig. 6d shows the distribution of particles with the vertical velocity opposite in sign to the previous vertical migratory pattern, i.e. the negative velocity is attributed to particles during flood, and positive, to particles during ebb, as shown in Fig. 4 d. The resultant distribution looks very different and reveals 2 tendencies in particle displacement. The majority of particles execute first northwestward, then northeastward drift in the middle of the channel, with a portion of the particles moving even to the southwest, in the opposite direction to the residual flow. The second group of particles, with low concentrations ( 3 per grid box) and separated from the main patch, executes shoreward, then along-coast drift. Particles of this group are found in the vicinity of the coast and also at the exit from the Dover Strait. A kind of stretching of particles in the cross-shore direction is induced by this vertical behavioural pattern. 
Table 1. Synthetic properties of dispersion for different groups of particles. rms: root-mean square

\begin{tabular}{|lccc|}
\hline Vertical migration pattern & $\begin{array}{c}\text { Major axis orientation } \\
\left({ }^{\circ}\right)\end{array}$ & $\begin{array}{c}\text { Along-axis rms displacement } \\
(\mathrm{km})\end{array}$ & $\begin{array}{c}\text { Cross-axis rms displacement } \\
(\mathrm{km})\end{array}$ \\
\hline No migration (960 particles) & 69 & 23.7 & 8.3 \\
No migration (9600 particles) & 69 & 24.0 & 8.3 \\
Light-dependent & 67 & 23.8 & 6.2 \\
Tidally cued & 76 & 20.0 & 6.8 \\
Locked to tidal currents & 73 & 12.6 & 6.3 \\
\hline
\end{tabular}

\section{Dispersion processes}

The PCA technique allows us to quantify the dispersion of particles and to discern the influence of vertical migration on horizontal spreading. We present in Table 1 the synthetic properties of dispersion: the orientation of the major axis of dispersion and the rms spreading of particles (relative to the centre of mass) along and across this axis. We analysed the horizontal distribution of 5 groups of particles, with and without vertical migration, at the end of the $18 \mathrm{~d}$ tracking period.

Both groups of 960 and 9600 neutrally buoyant particles reveal equivalent properties of dispersion, the direction and intensity of spreading, which confirm the observed similarity in the spatial distribution of particles and displacement of their centres of mass (Fig. 5a,b). Most striking is the difference in dispersion between the particle groups executing vertical motions. Particles with light-dependent vertical migration remain relatively close to the major axis of distortion (Fig. 6a). The rms magnitude of spreading along the minor axis (approximately in the cross-shore direction) is $6 \mathrm{~km}$, while the neutrally buoyant particles show higher cross-shore dispersion ( $\mathrm{rms}=8 \mathrm{~km}$ ) and a similar magnitude of dispersion in the along-shore direction. For all particle ensembles, the major axis tends to align with the direction of the dominant drift, and deviates clockwise from the north and from the coast line orientation by about $20^{\circ}$. Dispersion is weakest for particles executing vertical migration that is synchronised with tidal currents. The rms of spreading along the major axis is 2 times smaller than in the case of neutrally buoyant particles or particles executing lightdependent migration. Moreover, the dispersion of particles is more isotropic for this migratory pattern.

\section{DISCUSSION AND CONCLUSIONS}

The present study considers the coupled effect of barotropic (tidal) and baroclinic (forced by the freshwater input) circulation and the biological behaviour on larval transport in the EEC. It benefits from the increased spatial coverage of oceanographic and ichthyo- plankton data available from the larval drift experiment (Grioche et al. 1997). These data and earlier results of Land (1991) indicated flounder larval transport from the spawning area (central part of the EEC, offshore the Somme estuary) to nursery grounds located along the French coasts and extending from the Somme mouth to the southern part of the North Sea. In their later study, Grioche et al. (2000) admitted a hypothesis of diurnal (light dependent) vertical migration of flounder larvae and a possible effect of migration on the rate and direction of the horizontal larval transport.

To verify these hypotheses and to analyse the sensitivity of larval transport to various forcing components, we performed a number of particle-tracking model simulations. In contrast to previous studies (Graaf et al. 2004), we consider particle displacement in a 3-dimensional flow field driven by a combination of tides and buoyancy input. The results of simulations reveal that the interaction between the turbulence, freshwater and tidal forcing leads to particle trapping and produces spreading along the coast, with the maximum concentration of particles observed at a distance of approximately $20 \mathrm{~km}$ offshore. The accumulation of particles along the French coast is found to be associated with the ROFI dynamics under a hypertidal regime. The modelling study of Sentchev \& Korortenko (2005) shed light on the mechanisms of particle accumulation. The authors explored tidal circulation and transport in the ECC and have shown that, at the end of ebb, downward motions develop at the margin of the ROFI as a result of the surface current convergence, while near the coast and outside the ROFI the dominant vertical velocity is upward. At the end of flood, the situation is opposite: upward motions are detected along the coast, 15 to $20 \mathrm{~km}$ offshore. The downward motions are confined to a coastal area of 10 to $15 \mathrm{~km}$ width. It appears that particles are trapped and spread in the vertical direction within the water column by downward motions inside this convergence zone. The horizontal distribution of an ensemble of particles looks like the accumulation of particles. This feature of particle dynamics can be realistically represented only by means of a 3-dimensional hydrodynamic model. 
Numerical Lagrangian tracking demonstrates that neutrally buoyant particles are not only concentrated on the margin of the ROFI, but move northward along the coast. This along-coast drift of particles is also related to ROFI dynamics combined with tidal motions. As shown by Simpson (1997), interaction between the density-driven flow and tidal stirring gives rise to a low-frequency residual flow along the coast. Sentchev $\&$ Korotenko (2005) have analysed the spatial extension of the coastal current in the EEC and provided an estimate of the residual velocity, the magnitude of which varies within the range of 5 to $30 \mathrm{~cm} \mathrm{~s}^{-1}$. Field observations of surface currents along the northern coast of France (Sentchev \& Yaremchuk 2007) have also indicated an along-shore residual current with typical velocity of the order of $20 \mathrm{~cm} \mathrm{~s}^{-1}$. Thus, vertical motions, related to the surface current convergence within the ROFI system, in combination with the northward residual transport, strongly affect the vertical distribution of neutrally buoyant particles over multiple tidal cycles and can provide patchiness in the horizontal distribution of biological material. Without freshwater forcing, particles tend to be distributed in the vicinity of the shoreline and move northward with the residual tidal current at a lower speed. The analysis of our results suggests that the freshwater input controls the location of particle accumulation zones, whereas tidal currents determine the magnitude of the horizontal transport. The transport is strongly affected by the neap to spring variability of tidal current strength. Higher rates of displacement of the centre of mass of particles in Figs. $5 \& 6$ correspond to the period of primary spring tide, which occurred during the tracking period (Fig. 2d).

Numerical tracking experiments revealed that vertical migratory behaviour attributed to particles might cause relatively significant departure from the passive particle transport pattern. The essential differences concern the speed of northward drift of particles and the direction and intensity of dispersion. The drift and dispersion in the along-shore direction seem to be related. Low spreading and low speed of northward transport of particles are found together in the case of vertical migration synchronised with currents. Particles executing tidally cued and light-dependent migration move northward faster and exhibit stronger dispersion.

Regarding the dispersive part of transport, our simulations reveal that the intensity of spreading and the shape of particle distribution are strongly affected by vertical migratory behaviour, and also depend on the region (near-shore or offshore) where the drift occurs. Sentchev \& Korotenko (2005) diagnosed 2 current regimes in the EEC: the offshore regime with low effective dispersion and the near-shore regime of high dis- persion and stretching. In the near-shore waters, a relatively large horizontal dispersion in the along-shore direction is due to the interaction of tidally driven turbulence and the vertical shear generated by freshwater runoff. In turn, this mechanism interacts with the horizontal shear of residual currents, giving further increase of the effective dispersion in the direction of the residual current. The mechanisms of horizontal dispersion by oscillatory tidal and residual currents are also discussed in detail by Zimmerman (1986). The studies of Sentchev \& Korotenko (2005) and Zimmerman (1986) suggest that shear dispersion is the basic mechanism responsible for strong deformation of a group of particles along the French coast in the ROFI system of the EEC. Our modelling results are in close agreement with these studies.

Experiments with vertically migrating particles show that the cross-shore dispersion is low for all of the considered migratory patterns. Particles, migrating at a diurnal or semidiurnal period, spend a part of the time in the middle and near-bottom layers, where the horizontal gradient of velocity is weaker than in the upper layer. Thus, the resultant horizontal cross-shore dispersion (Table 1) is weaker than that in neutrally buoyant particles travelling in the upper layer. We quantify the difference as $30 \%$.

In the case of tidally cued vertical migration, vertical velocity depends upon hydrostatic pressure tendencies. In the EEC, the variation of sea surface height and currents over a tidal period is characterised by a strong asymmetry: the rising tide is $2 \mathrm{~h}$ shorter than the falling tide (Fig. 3b). This implies that after the current reversal at low water (LW), particles tend to reside in deeper layers and travel southward with lower velocity during a shorter period of time. Whereas particles travelling northward, after the current reversal at high water (HW), are found in the upper layer with a stronger current. The period of northward excursion of particles in this case is longer. In the EEC, tidal currents advance the sea surface height variation by approximately $2 \mathrm{~h}$. If we assign this phase lag to migrating particles, the rate of northward drift of the ensemble of particles drops (Fig. 6c). We relate this effect to the vertical distribution of particles in different periods of the tidal cycle. Particles are found near the surface before and after the current reversal at HW, and at depths during the current reversal at LW (Fig. 2c). When the tidal current is strong, both upward- and downward-migrating particles are found at mid-depths. In this case, the difference between southward and northward excursion length appears to be smaller. These results suggest that the phase lag between the sea level and tidal current evolution, basically variable in space, might affect the intensity of larval drift differently in different parts of the basin, or might create conditions allowing 
marine organisms to move in the opposite direction to the dominant flow (Hill 1994).

In summary, our computations have revealed the accumulation of neutrally buoyant and vertically migrating particles along the French coast, $20 \mathrm{~km}$ offshore. This happens because the interaction between the freshwater input and tidal currents produces particle trapping and spreading in a vertical direction within a convergence zone located on the ROFI seaward margin. Tides and buoyancy input induce the net along-shore northward transport, the intensity of which depends on the phase of $14 \mathrm{~d}$ tidal cycle and the vertical migratory pattern. Results of numerical modelling have been compared with the observed larval distributions and have shown consistency with the data. We have demonstrated that the vertical migratory behaviour of larvae can be an effective mechanism causing a significant departure from the transport pattern of passive tracers. It might also control the relative dominance of either retention or downstream advection of the larvae in the EEC. The vertical migration synchronised with tidal currents provides the lowest along-shore dispersion and a small rate of the northward drift of particles. Diurnal (light dependent) migration tends to decrease the magnitude of the cross-shore dispersion, whereas tidally (sea level) cued vertical migration induces a fast northward drift. Simulations with migrating particles revealed a strong sensitivity of the model to vertical migratory behaviour. Comparison with the field data led us to speculate that tidally (sea level) cued migration is most likely to occur. This behaviour, assigned to model particles, shows reasonable agreement with the observed distribution of abundances and a reasonable rate of northward migration. Though knowledge of the behavioural properties of larvae might help to explain horizontal transport, comparison of modelling results with observed abundances is important but far from being trivial. First, the sampled region covers only a part of the spawning grounds of flounder. Secondly, the spatial distribution of the larvae is affected, not only by the dynamic properties of flow and the biological behaviour of species, but also by the spatial patterns in survivorship, which are poorly known. Both accurate numerical simulations and large-scale sampling strategies, with precise observations of larval migratory behaviour and survival, are necessary for improving the efficiency of larval transport prediction.

Acknowledgements. This study was conducted as part of the project supported by CNRS Grant 12217. We thank A. Grioche and P. Koubbi for providing the biological data, and M. Yaremchuk for useful ideas and valuable comments on our manuscript. Constructive remarks and critical comments by anonymous referees and the scientific editors were very helpful in improving the paper.

\section{LITERATURE CITED}

Bartsch J (1988) Numerical simulation of the advection of vertically migrating herring larvae in the North Sea. Meeresforschung 32:30-45

Bartsch J, Coombs SH (2001) An individual-based growth and transport model of the early life-history stages of mackerel (Scomber scombrus) in the eastern North Atlantic. Ecol Model 138:127-141

Blumberg AF, Mellor GL (1987) A description of a threedimensional hydrodynamic model of New York harbour region. J Hydraul Eng 125(8):799-816

Boeuf G, Payanb P (2001) How should salinity influence fish growth? Comp Biochem Physiol C 130:411-423

Boss A, Thiel R, Nellen W (1995) Distribution and transport mechanisms of the upstream migrating flounder larvae, Pleuronectes flesus Linnaeus, 1758, in the tidal Elbe River, Germany. ICES CM M41:1-10

Brown CA, Jackson GA, Brooks DA (2000) Particle transport through a narrow tidal inlet due to tidal forcing and implications for larval transport. J Geophys Res 105(C10): 24141-24156

Burke JS, Tanakab M, Seikai S (1995) Influence of light and salinity on behaviour of larval Japanese flounder (Paralichthys olivaceus) and implications for inshore migration. Neth J Sea Res 34:59-69

Burke JS, Ueno M, Tanaka Y, Walsh H 5 others (1998) The influence of environmental factors on early life history patterns of flounders. J Sea Res 40:19-32

Campos WL, Kloppmann M, von Westernhagen H (1994) Inferences from the horizontal distribution of dab Limanda limanda and flounder Platichthys flesus larvae in the south-eastern North Sea. Neth J Sea Res 32:277-286

Emery WJ, Thomson RE (1997) Data analysis methods in physical oceanography. Pergamon, New York

Flather RA (1976) A tidal model of the north-west European continental shelf. Mem Soc R Sci Liege Ser 6 X:141-164

Franks PJS (1992) Sink or swim: accumulation of biomass at fronts. Mar Ecol Prog Ser 82:1-12

Graaf M, Jager Z, Vreugdenhil CB, Elorche M (2004) Numerical simulations of tidally cued vertical migrations of flatfish larvae in the North Sea. Estuar Coast Shelf Sci 59:295-305

Grioche A, Koubbi P, Sautour B (1997) Ontogenic migration of Pleuronectes flesus larvae in the eastern English Channel. J Fish Biol 51(Suppl A):385-396

Grioche A, Harlay X, Koubbi P, Fraga Lago L (2000) Vertical migration of fish larvae: Eulerian and Lagrangian observations in the eastern English Channel. J Plankton Res 22: $1813-1828$

Hill AE (1994) Horizontal zooplankton dispersal by diel vertical migration in S2 tidal currents on the northwest European continental shelf. Cont Shelf Res 14:491-506

Hunter J, Craig P, Phillips H (1993) On the use of randomwalk models with spatially-variable diffusivity. J Comp Physiol 106:366-376

Jenkins GP, Black KP, Keough MJ (1999) The role of passive transport and the influence of vertical migration on the pre-settlement distribution of a temperate, demersal fish: numerical model predictions compared with field sampling. Mar Ecol Prog Ser 184:259-271

Jenkins GP, Black KP, Hamer PA (2000) Determination of spawning areas and larval advection pathways for King George whiting in southeastern Australia using otolith microstructure and hydrodynamic modelling. I. Victoria. Mar Ecol Prog Ser 199:231-242

Le Provost C, Lyard F, Molines JM, Genco ML, Rabilloud F (1995) A hydrodynamic ocean tidal model improved by 
assimilating a satellite-derived data set. J Geophys Res 103(C3):5513-5529

Mellor GL, Yamada T (1982) Development of a turbulence closure model for geophysical fluid problems. Rev Geophys Space Phys 20:851-875

Nielsen E, Bagge O, MacKenzie BR (1998) Wind-induced transport of plaice (Pleuronectes platessa) early life-history stages in the Skagerrak-Kattegat. J Sea Res 39:11-28

Sentchev A, Korotenko K (2004) Stratification and tidal current effects on larval transport in the eastern English Channel: observations and 3D modelling. Environ Fluid Mech 4:305-331

Sentchev A, Korotenko K (2005) Dispersion processes and transport pattern in the ROFI system of the eastern English Channel derived from a particle-tracking model. Cont Shelf Res 25:2294-2308

Sentchev A, Yaremchuk M (2007) VHF radar observations of surface currents off the northern Opal coast in the eastern English Channel. Cont Shelf Res (in press)

Simpson JM (1997) Physical processes in the ROFI regime. J Mar Syst 12:3-15

Smagorinsky J (1963) General circulation experiments with the primitive equations. I. The basic experiment. Mon Weather Rev 91:99-164

Van der Land MA (1991) Distributions of flatfish eggs in the

Editorial responsibility: Alejandro Gallego (Contributing

Editor), Aberdeen, UK
1989 egg surveys in the southeastern North Sea, and mortality of plaice and sole eggs. Neth J Sea Res 27: 353-366

Van der Veer HW, Ruardij P, Van den Berg AJ, Ridderinkhof $\mathrm{H}$ (1998) Impact of interannual variability in hydrodynamic circulation on egg and larval transport of plaice Pleuronectes platessa L. in the southern North Sea. J Sea Res 39:29-40

Visser AW (1997) Using random walk models to simulate the vertical distribution of particles in a turbulent water column. Mar Ecol Prog Ser 158:275-281

Werner FE (1995) A field test case for tidally forced flows: a review of the tidal flow forum. In: Lynch DR, Davies AM (eds) Quantitative skill assessment for coastal ocean models. Coast Estuar Stud 47:269-283

Werner FE, Quinlan JA, Blanton BO, Luettich RA (1997) The role of hydrodynamics in explaining variability in fish populations. J Sea Res 37:195-212

Xie L, Eggleston DB (1999) Computer simulations of windinduced estuarine circulation patterns and estuary-shelf exchange processes: the potential role of wind forcing on larval transport. Estuar Coast Shelf Sci 49:221-234

Zimmerman JTF (1986) The tidal whirlpool: a review of horizontal dispersion by tidal and residual currents. Neth $\mathrm{J}$ Sea Res 20:133-154

Submitted: July 11, 2006; Accepted: June 28, 2007 Proofs received from author(s): September 1, 2007 